\title{
A decision-support tool to inform Australian strategies for preventing suicide and suicidal behaviour
}

\author{
Andrew Page ${ }^{a, f}$, Jo-An Atkinsonn,c, Mark Heffernand ${ }^{\mathrm{b}}$, Geoff McDonnell ${ }^{\mathrm{b}}$ \\ and Ian Hickie ${ }^{e}$
}

a Centre for Health Research, Western Sydney University, NSW, Australia

b The Australian Prevention Partnership Centre, Sax Institute, Sydney, NSW, Australia

c School of Medicine, University of Sydney, NSW, Australia

d Dynamic Operations, Sydney, NSW, Australia

e Brain and Mind Centre, University of Sydney, NSW, Australia

${ }^{\dagger}$ Corresponding author: a.page@westernsydney.edu.au

\section{Article history}

Publication date: April 2017

Citation: Page A, Atkinson J, Heffernan M, McDonnell G, Hickie I. A decision-support tool to inform Australian strategies for preventing suicide and suicidal behaviour. Public Health Res Pract. 2017;27(2):e2721717. doi: http://dx.doi. org/10.17061/phrp2721717

\section{Key points}

- We developed a system dynamics model of suicide prevention in Australia that can be used as a decision-support tool for policy makers and communities

- The model considers the hypothesised impacts of suicide prevention strategies proposed for current population intervention studies in Australia

- Findings suggest that the largest proportion of prevented suicides was associated with general practitioner training in the identification of suicide risk, and coordinated aftercare approaches following a suicide attempt

\section{Abstract}

Dynamic simulation modelling is increasingly being recognised as a valuable decision-support tool to help guide investments and actions to address complex public health issues such as suicide. In particular, participatory system dynamics (SD) modelling provides a useful tool for asking high-level 'what if' questions, and testing the likely impacts of different combinations of policies and interventions at an aggregate level before they are implemented in the real world.

We developed an SD model for suicide prevention in Australia, and investigated the hypothesised impacts over the next 10 years (2015-2025) of a combination of current intervention strategies proposed for population interventions in Australia: 1) general practitioner (GP) training, 2) coordinated aftercare in those who have attempted suicide, 3) school-based mental health literacy programs, 4) brief-contact interventions in hospital settings, and 5) psychosocial treatment approaches.

Findings suggest that the largest reductions in suicide were associated with GP training (6\%) and coordinated aftercare approaches (4\%), with total reductions of $12 \%$ for all interventions combined. This paper highlights the value of dynamic modelling methods for managing complexity and uncertainty, and demonstrates their potential use as a decision-support tool for policy makers and program planners for community suicide prevention actions.

\section{Introduction}

Suicide remains a leading cause of death in young people, and contributes significant social, economic and health system costs to Australia. The extent to which specific suicide prevention policies and programs over the past two 
decades have had an impact on population-level suicide rates in Australia is unclear. ${ }^{1}$ This is despite government and nongovernment investment, senate committee inquiries, implementation frameworks, and efforts to improve coordination of programs and services. ${ }^{2-5}$

The ability to design effective policy for suicide prevention in populations is challenged by the complex aetiology of suicide, limited generalisable evidence for interventions that prevent suicide in populations, and the quality and timeliness of surveillance data on suicidal behaviour (and other intermediate indicators) to measure the effect of suicide prevention initiatives.

There are also often incongruous priorities between researchers, policy makers and service providers. The time, scope and rigour required for conducting research to implement and evaluate combined multilevel approaches to suicide prevention using traditional epidemiological approaches often do not match with the priorities and timelines of service providers, policy makers and local communities, who usually require local or context-specific information. , $^{6}$

Although there is some evidence for effective prevention strategies in particular contexts ${ }^{8}$, it is unlikely that a single intervention will have populationlevel impacts on suicide rates, given the interplay of aetiological factors associated with suicidal behaviour within a complex health and social services system. Interventions that may have promising effects on preventing suicide in one context may not be generalisable to other contexts, and their likely effects over time and in combination are unknown. These issues can be addressed by acknowledging this complexity, and applying systems modelling tools and approaches to support decision making and guide prevention initiatives. ${ }^{6}$

This article addresses some of these challenges by combining objective data on suicidal behaviour with evidence reviews of suicide prevention strategies to develop a system dynamics (SD) model. This is a potential tool for policy makers to provide timely and population-specific information on the incidence of suicidal behaviour. The model demonstrates a potential platform for integrating diverse evidence sources into an analytic tool that can allow policy makers to explore the likely impacts of different policy and intervention scenarios over the short and longer terms in a robust, risk-free and low-cost way. That is, it can be used to conduct virtual experiments where real-world studies may not be feasible.

\section{A system dynamics model}

The use of system science modelling methods, such as SD (and also agent-based modelling and discrete event simulation), is becoming more prominent in the health sector because of the potential of these models to address policy making challenges for complex problems. ${ }^{7}$ These methods have a long history in engineering, economics, defence and ecology, and have more recently been useful in appropriately characterising the complex nature of the health sector - including evaluating operational aspects of healthcare capacity and demand, patient flows, and disease screening ${ }^{7}$, as well as a range of disease risk factors and outcomes. ${ }^{6,9,10}$ An SD approach has not previously been applied to the topic of suicide; however, the complex aetiology of suicidal behaviour and the range of potentially interacting prevention strategies suggest that this approach may be useful to inform policy responses.

We developed an SD model to reflect a series of suicidal states in the Australian population, ranging from no suicidal thoughts or behaviours, to suicidal ideation, to the planning of suicidal acts, to attempted suicide and completed suicide (Figure 1; see also Supplementary Figure 1 for model structure, available from: www. saxinstitute.org.au/tables-suicide-prevention-tool). This progression from ideation to behaviour, modified by level of intent and lethality of method, is broadly consistent with current conceptualisations of suicidal behaviour, although debate remains about the nomenclature of the range of suicidal behaviour that occurs in populations. ${ }^{11}$ Conceptualising the pathway of suicidal behaviour in this

Figure 1. Summary structure of the system dynamics model of Australian suicide

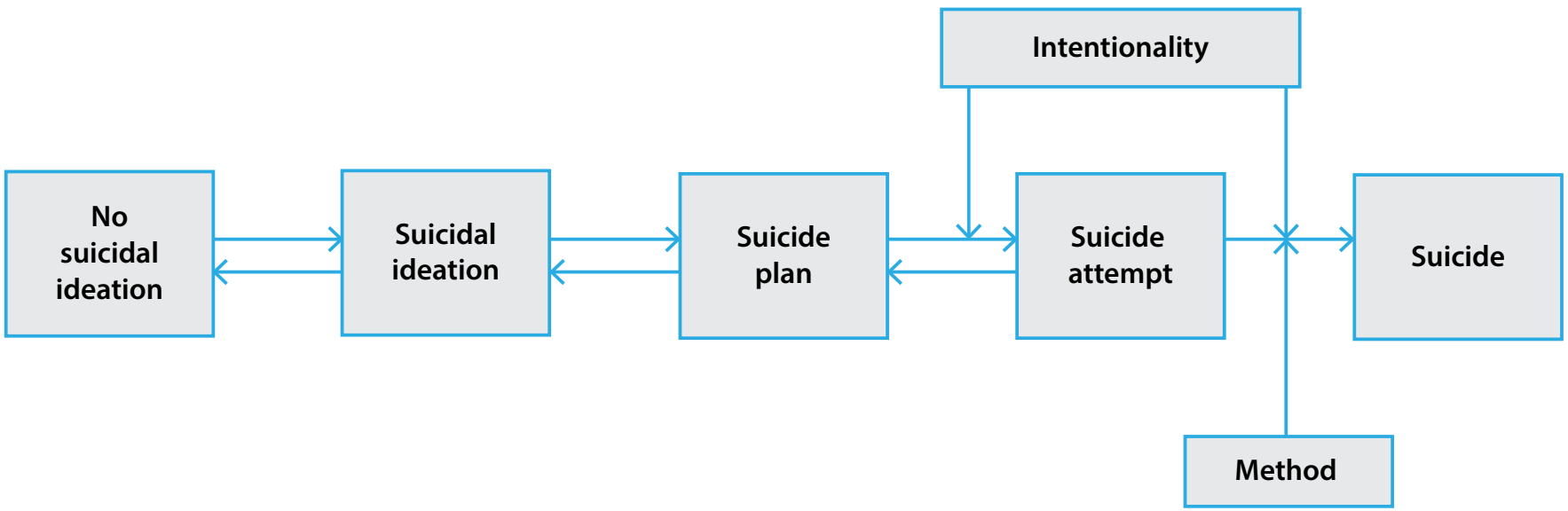


manner also enabled representative data sources to be used to validate the model on the two key outcomes of interest: cases of hospital-treated attempted suicide and cases of suicide.

\section{Model inputs}

The model was developed using historical time series of hospital-treated attempted suicide and cases of suicide from 2000 to 2014, for males and females separately. Models were stratified by sex to reflect the three- to four-fold difference in the incidence of suicide between males and females. Nationally representative estimates of suicidal ideation and suicide planning for males and females were obtained from the most recent National Survey of Mental Health and Wellbeing ${ }^{12}$, and the level of suicidal intent for suicide attempts was obtained from the Australian National Survey of Self Injury ${ }^{13}$ (Supplementary Tables 1-4, available from: www.saxinstitute.org.au/ tables-suicide-prevention-tool). The most common methods of suicidal behaviour for suicide attempts and suicides were also incorporated, as a reflection of the differing methods used by males and females, and also the differing levels of suicidal intent and lethality. These methods comprised 'self-poisoning' (International Statistical Classification of Diseases and Related Health Problems [ICD-10] codes X60-X69), 'hanging' (X70), 'drowning' (X71), 'firearms' (X72-X74), 'cutting' (X78), 'jumping from a high place' (X80) and 'other' (X75-X77, X79, X81-X84).

A recent systematic review of peer-reviewed intervention studies was used to extract intervention effects for different health service-related suicide prevention initiatives ${ }^{14}$ (Supplementary Table 5, available from: www.saxinstitute.org.au/tables-suicideprevention-tool). The strategies described in this review were selected because they are currently the subject of a large-scale community trial (www.lifespan.org. $\mathrm{au}$ ), and have been the recent focus of debate among population health researchers ${ }^{15,16}$ and of government funding strategies. The population preventive fractions reported in this review were used as inputs to intervention mechanisms that modify net rates of movement of the population from one state to another. The resulting estimated number of suicides averted (as described below) incorporates these hypothesised intervention mechanism effects, which include sources of realworld inertia and delay (such as time to scale up interventions, service provider adoption, patient uptake of interventions), and their impact on feedback flows in the model.

\section{Modelling the impacts of interventions}

Three approaches were considered to assess the hypothesised impact of the interventions described above over a forecast period of 2015-2025. First, each of the service interventions was considered separately to forecast its impact on attempted suicide and suicide. Second, all the service interventions were considered in combination. Third, hypothetical changes in the lethality of each of the selected methods of suicidal behaviour were considered. For illustrative purposes, these model runs assumed a 20\% absolute reduction in lethality for each of the methods described above - that is, to assess the hypothesised impact on subsequent suicide if the lethality of (for example) hanging could be reduced by $20 \%$. Finally, the combined effects of the health service interventions plus the combined effects of reductions in lethality of method were considered.

The interactive model can be accessed online (saxinstitute.scem.uws.edu.au/netsims/suicide-1/suicide_ v403/index.html) to investigate alternative scenarios.

\section{Results from the model}

The model estimated a historical time series (2000-2014) for males and females in the Australian population (Figure 2A) that was within 5\% of the observed suicide data for an equivalent period. The model forecast an increase in suicide frequency from 2015 to 2025 from 2244 to 2861 for males and 713 to 935 for females.

Comparative runs of the model investigating the separate impacts of interventions suggest that general practitioner (GP) training in the identification and management of patients presenting with risk factors for suicide (such as mental illness) or suicidal ideation, and coordinated assertive aftercare for those who present to hospital services following a suicide attempt result in the largest proportion of suicides prevented over the forecast period. For GP training, approximately $6 \%$ of suicide cases were prevented in males and females (Figure 2B; Table 1). The other interventions had negligible impacts on suicide trends when simulated individually. In combination, the estimated proportion of prevented suicides for all service interventions was $12 \%$ for both males and females (Figure 2B; Table 1).

Simulated reductions in lethality of method also resulted in declines in suicide over the forecast period (2015-2025). For both males and females, the largest proportion of prevented suicides was for hanging (7\% in males; $5 \%$ in females) (Figure 2C; Table 1). In combination, the estimated proportion of prevented suicides for a reduction in lethality of method of $20 \%$ for all of the selected methods was $10 \%$ for males and females (Figure 2C; Table 1).

In models combining the effects of all health service interventions plus reductions in lethality of method, the estimated proportion of prevented suicides was $22 \%$ for both males and females (Figure 2D; Table 1). 
Figure 2. Model outputs for Australian suicide (2001-2025) and comparative model runs for the forecast period 2015-2025

(A) Observed and modelled suicides

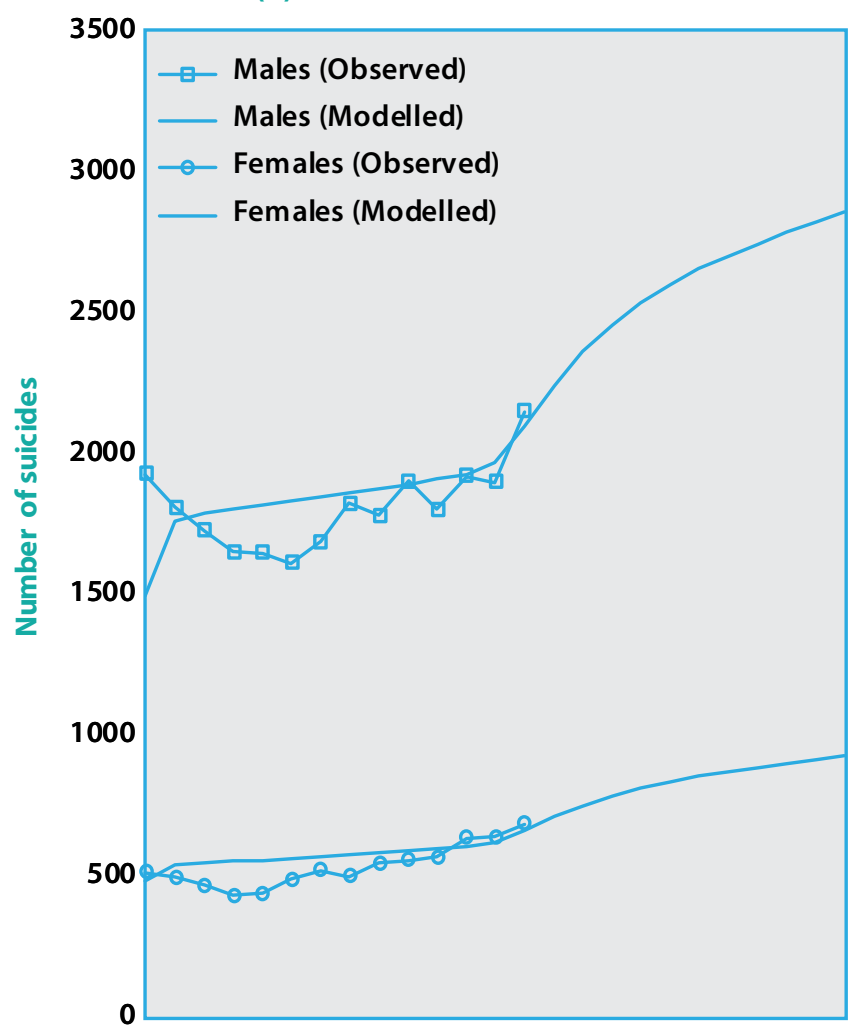

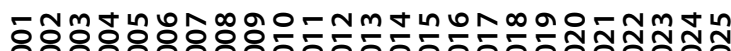

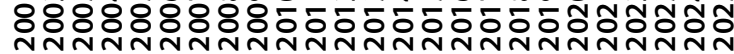

(C) Impacts of $\mathbf{2 0 \%}$ reduction in lethality

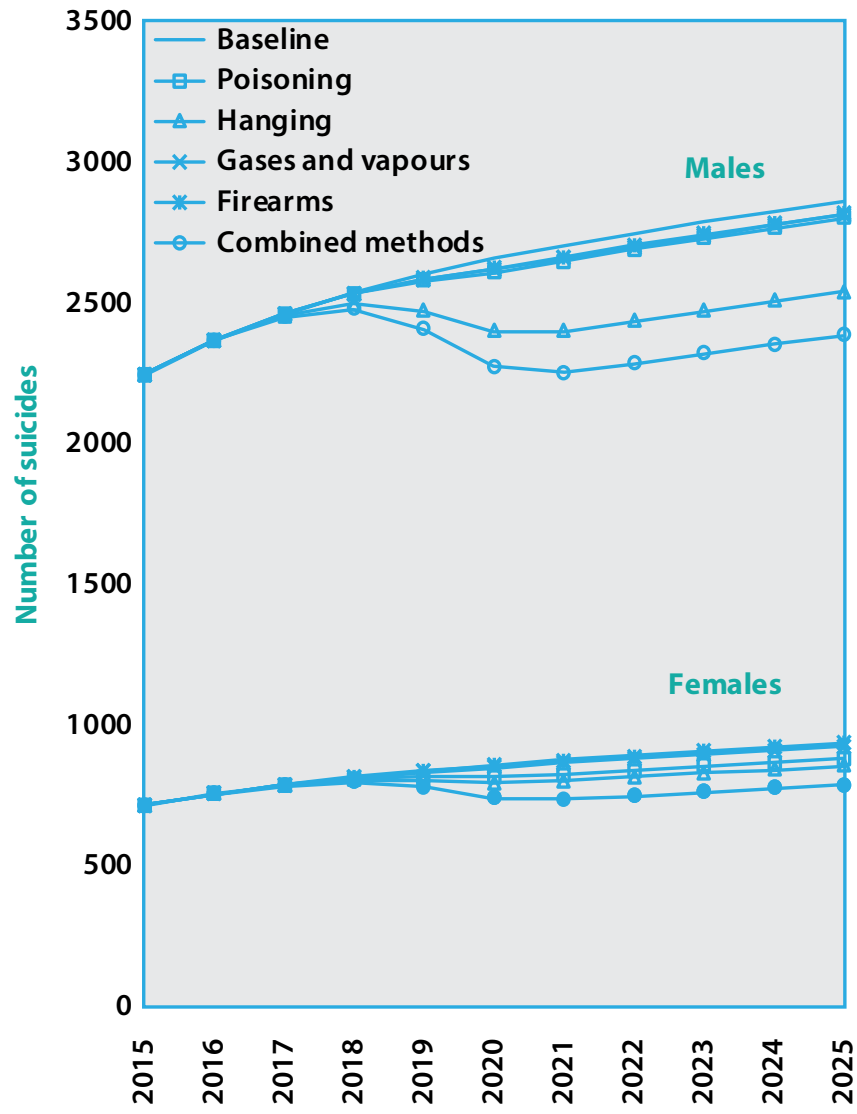

(B) Service interventions

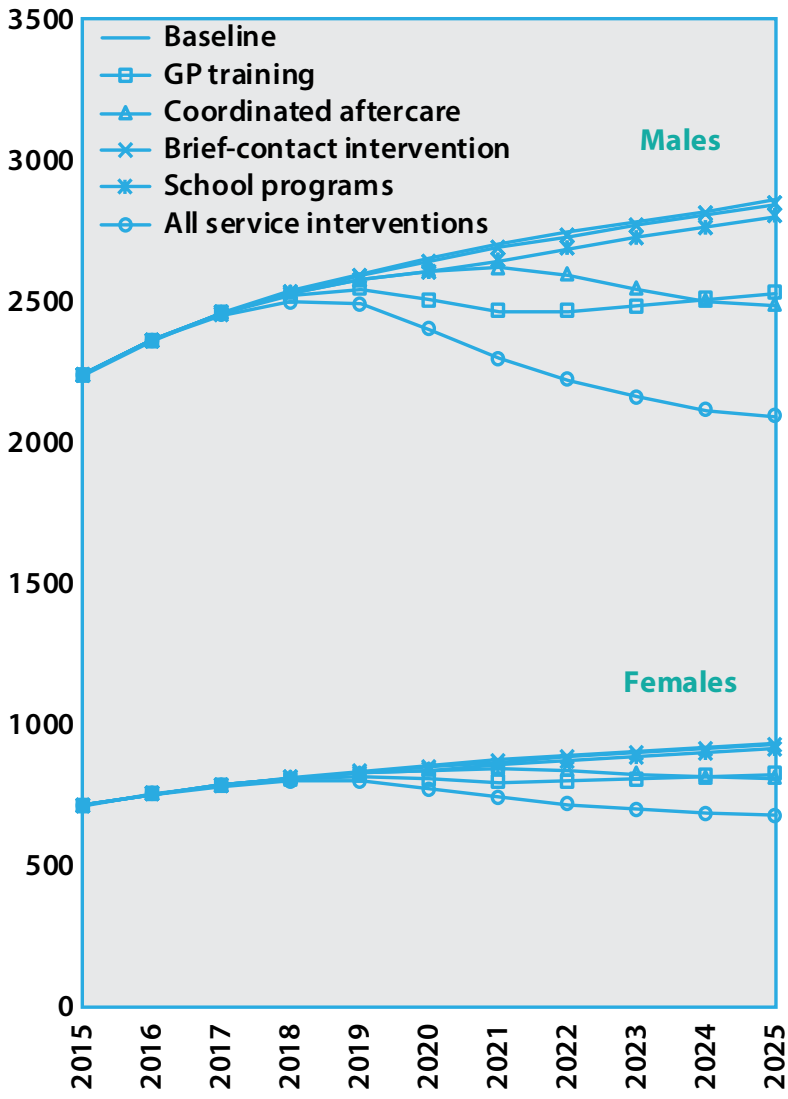

(D) Combined effects of service interventions and reduction in lethality

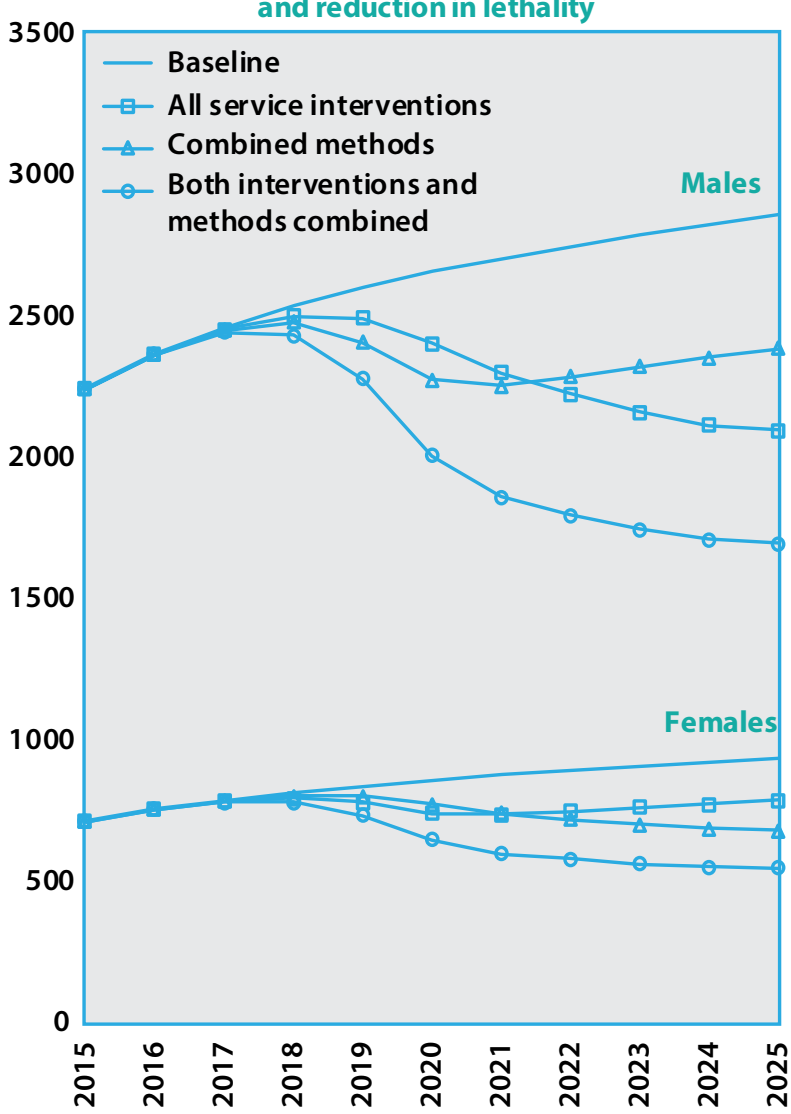


Table 1. Summary of estimated reductions in suicide from 2015 to 2025 using combinations of selected interventions and reductions in lethality of method

\begin{tabular}{|c|c|c|c|c|c|c|c|}
\hline \multirow[b]{2}{*}{ Measure } & \multirow[b]{2}{*}{ Type } & \multicolumn{3}{|c|}{ Males } & \multicolumn{3}{|c|}{ Females } \\
\hline & & Cumulative cases ${ }^{\mathrm{a}}$ & $\begin{array}{l}\text { Cases } \\
\text { averted }\end{array}$ & $\%$ reduction & Cumulative cases ${ }^{\mathrm{a}}$ & $\begin{array}{l}\text { Cases } \\
\text { averted }\end{array}$ & $\%$ reduction \\
\hline $\begin{array}{l}\text { Total suicides } \\
\text { (no intervention) }\end{array}$ & na & 28791 & 0 & 0.0 & 9289 & 0 & 0.0 \\
\hline \multirow[t]{6}{*}{$\begin{array}{l}\text { Service } \\
\text { interventions }\end{array}$} & $\begin{array}{l}\text { General } \\
\text { practitioner } \\
\text { training }\end{array}$ & 27108 & 1684 & 5.8 & 8741 & 548 & 5.9 \\
\hline & $\begin{array}{l}\text { Coordinated } \\
\text { aftercare }\end{array}$ & 27550 & 1241 & 4.3 & 8877 & 413 & 4.4 \\
\hline & $\begin{array}{l}\text { Brief-contact } \\
\text { intervention }\end{array}$ & 28698 & 93 & 0.3 & 9255 & 35 & 0.4 \\
\hline & $\begin{array}{l}\text { School } \\
\text { programs }\end{array}$ & 28431 & 361 & 1.3 & 9171 & 119 & 1.3 \\
\hline & $\begin{array}{l}\text { Psychosocial } \\
\text { programs }\end{array}$ & 28140 & 652 & 2.3 & 9068 & 222 & 2.4 \\
\hline & $\begin{array}{l}\text { Combined } \\
\text { service } \\
\text { interventions }\end{array}$ & 25358 & 3434 & 11.9 & 8153 & 1137 & 12.2 \\
\hline \multirow{5}{*}{$\begin{array}{l}20 \% \text { reduction } \\
\text { in method } \\
\text { lethality }\end{array}$} & Poisoning & 28418 & 374 & 1.3 & 8951 & 338 & 3.6 \\
\hline & Hanging & 26777 & 2015 & 7.0 & 8793 & 497 & 5.3 \\
\hline & $\begin{array}{l}\text { Gases and } \\
\text { vapours }\end{array}$ & 28483 & 309 & 1.1 & 9222 & 68 & 0.7 \\
\hline & Firearms & 28514 & 277 & 1.0 & 9274 & 15 & 0.2 \\
\hline & $\begin{array}{l}\text { Combined } \\
\text { methods } \\
\text { above }\end{array}$ & 25812 & 2979 & 10.3 & 8371 & 918 & 9.9 \\
\hline $\begin{array}{l}\text { Combined } \\
\text { service } \\
\text { interventions } \\
\text { and reduction } \\
\text { in lethality }\end{array}$ & na & 22572 & 6219 & 21.6 & 7243 & 2046 & 22.0 \\
\hline
\end{tabular}

na $=$ not applicable

a Estimated number of total suicides accumulated over 2015-2025

\section{Summary and implications of findings}

This paper describes the application of an SD model of suicide prevention in Australian males and females, which also incorporates current best evidence relating to strategies for prevention. ${ }^{14}$ In comparisons of the simulated effects of prevention strategies, the largest estimated impacts on declines in suicide were for GP training ${ }^{17}$ and coordinated aftercare. ${ }^{18}$ Simulated reductions in lethality of method by $20 \%$ for selected methods of suicidal behaviour (that is, assuming that interventions were available to reduce lethality of method) also suggested that the largest declines would be achieved with reductions in the lethality of hanging.

The National Mental Health Commission² has called for a $50 \%$ reduction in the number of suicides and suicide attempts over the next decade. Based on the interventions currently being considered as the best approaches to prevent suicide, findings suggest that this $50 \%$ reduction will not be achieved by these strategies alone. Additionally, the methods that are most amenable to intervention (such as self-poisoning, jumping and firearms) appear to have the smallest impact on suicide declines, whereas hypothesised changes to lethality of 
hanging - a method that is not amenable to intervention had the largest estimated impact on suicide declines over the forecast period.

Although the SD model is able to account for behavioural and population dynamics that affect population-level changes over time in intentional self-harm, aggregate models such as these are an oversimplification that do not consider the complex individual mechanisms and trajectories associated with suicidal behaviour. Agent-based models may be more appropriate in capturing these mechanisms. However, the application of SD applies a level of mathematical rigour that has not previously been applied to trends in suicide, and is consistent with observed data inputs at the aggregate population level.

The model is also calibrated on routinely collected data on mortality and hospital admissions. There is some underenumeration of suicide cases due to the misclassification of suicides to ICD codes relating to unintentional injury and events of 'undetermined intent'; however, this does not preclude the use of these data, particularly in studies of time-series analyses. Additionally, hospital admissions data are likely to underestimate the total population level of attempted suicide, in that the data on suicide attempts capture only those cases that are serious enough to warrant medical intervention.

The interventions incorporated into the model represent a limited set of potentially important interventions. The extent to which the underlying relative risk estimates are applicable to the Australian and other country contexts warrants consideration, as do the representativeness and precision of the prevalence estimates used to calculate the population preventive fractions. However, in the context of using SD models to inform the prioritisation of evidence based interventions, SD models provide hypothesised effects that can subsequently be assessed using empirical data. Other evidence on potentially effective interventions from observational studies (for example, relating to educational achievement ${ }^{19}$, unemployment ${ }^{20}$ or early intervention for mental illness ${ }^{21}$ ) may be additional areas for consideration in subsequent dynamic models of suicidal behaviour. SD models can be calibrated for any given geographic context or subpopulation of interest, and are strengthened through participatory model-building exercises involving local stakeholders - a central principle that ensures that the resulting decision-support tool is directly relevant to decision makers. ${ }^{6}$

This article demonstrates how an SD model can be used as a potential decision-support tool for policy makers to ask 'what if' questions, and to test the potential impacts of intervention and policy scenarios over time before implementing solutions in the real world. Recent advances in modelling software and transparent participatory approaches are enabling suicide prevention researchers, policy makers, practitioners, consumer representatives and modellers to collaboratively develop such models and draw on diverse evidence sources. This offers promise in providing tools that are better aligned to the decision-support needs of policy makers and facilitate consensus building for action. This modelling tool is proposed as an adjunct to standard program design and evaluation approaches, and does not preclude the use of prospective evaluation studies based on primary data collection to address deficiencies in local data and assess joint effects of intervention combinations. Rather, SD models provide an additional way to engage stakeholders, and prioritise resources and interventions in the design and evaluation of suicide prevention initiatives.

\section{Acknowledgements}

This article is based on research funded by a Western Sydney University Research Partnership Grant.

\section{Competing interests}

$\mathrm{MH}$ has received money from the Sax Institute for consultancy services. IH is an unpaid board member of the Psychosis Australia Trust. IH receives money from the National Mental Health Commission for his role as a Mental Health Commissioner and from Medibank Private as a member of its Medical Advisory Panel. He has previously received payment as a member of the Bupa Australia Medical Advisory Board and for lectures from Servier, Janssen, AstraZeneca and Pfizer.

\section{Author contributions}

AP contributed to the study conception and design, literature review, analysis and interpretation, and drafting and editing of the manuscript. JA contributed to the study design, analysis and interpretation, and critical editing of the manuscript. $\mathrm{MH}$ and $\mathrm{GM}$ undertook development of the SD model, analysis and interpretation, and critical editing of the manuscript. $\mathrm{MH}$ also carried out the model coding. IH contributed to the study design, interpretation of results and critical editing of the manuscript.

\section{References}

1. Page A, Taylor R, Gunnell D, Carter G, Morrell S, Martin G. Effectiveness of Australian youth suicide prevention initiatives. Br J Psychiatry. 2011;199:423-9.

2. National Mental Health Commission. Contributing lives, thriving communities: report of the national review of mental health programmes and services. Sydney: NMHC; 2014 [cited 2017 Mar 17]. Available from: www. mentalhealthcommission.gov.au/our-reports/contributinglives,-thriving-communities-review-of-mental-healthprogrammes-and-services.aspx 
3. Australian Institute of Family Studies. Youth suicide prevention programs and activities: national stocktake October 1999. Melbourne: Australian Institute of Family Studies; 1999 [cited 2017 Mar 22]. Available from: aifs. gov.au/sites/default/files/publication-documents/youth_ suicide_prevention_programs_and_activities_national_ stocktake_october_1999.pdf

4. Department of Health and Ageing. Living is for everyone (LIFE): a framework for prevention of suicide in Australia. Canberra: Commonwealth of Australia; 2008 [cited 2017 Mar 22]. Available from: www.livingisforeveryone. com.au/uploads/docs/LIFE_framework-web.pdf

5. The Senate Community Affairs References Committee. The hidden toll: suicide in Australia. Canberra: Commonwealth of Australia; 2010 [cited 2017 Mar 22]. Available from: www.aph.gov.au/Parliamentary_Business/ Committees/Senate/Community_Affairs/Completed_ inquiries/2008-10/suicide/report/index

6. Atkinson J, Page A, Wells R, Milat A, Wilson A. A modelling tool for policy analysis to support the design of efficient and effective policy responses to complex public health problems. Implement Sci. 2015;10:26.

7. Atkinson J, Wells R, Page A, Wilson A, Dominello A, Haines M. Applications of systems dynamics modelling to support health policy. Public Health Res Pract. 2015;25(3):e2531531.

8. Mann JJ, Apter A, Bertolote J, Beautrais A, Currier D, Haas A, et al. Suicide prevention strategies: a systematic review. JAMA. 2005;294(16):2064-74.

9. Cavana RY, Clifford LV. Demonstrating the utility of system dynamics for public policy analysis in New Zealand: the case of excise tax policy on tobacco. Syst Dyn Rev. 2006;22(4):321-48.

10. Homer JB, Hirsch GB. System dynamics modeling for public health: background and opportunities. Am J Public Health. 2006;96(3):452-8.

11. Silverman MM, Berman AL, Sanddal ND, O'Carroll PW, Joiner TE. Rebuilding the tower of Babel: a revised nomenclature for the study of suicide and suicidal behaviors. Part 1: background, rationale, and methodology. Suicide Life Threat Behav. 2007;37(3):248-63.
12. Johnston AK, Pirkis JE, Burgess PM. Suicidal thoughts and behaviours among Australian adults: findings from the 2007 National Survey of Mental Health and Wellbeing. Aust N Z J Psychiatry. 2009;43(7):635-43.

13. Martin G, Swannell SV, Hazell PL, Harrison JE, Taylor AW. Self-injury in Australia: a community survey. Med J Aust. 2010;193(9):506-10.

14. Krysinska K, Batterham PJ, Tye M, Shand F, Calear AL, Cockayne $\mathrm{N}$, et al. Best strategies for reducing the suicide rate in Australia. Aust N Z J Psychiatry. 2016;50(2):115-8.

15. Hegerl U, Kohls E. Synergistic effects of multi-level suicide preventive interventions: Important, but difficult to disentangle. Aust N Z J Psychiatry. 2016;50(2):178-9.

16. Pirkis J. The population-level effectiveness of suicide prevention strategies that might be used in a systems-based approach. Aust N Z J Psychiatry. 2016;50(2):179-80.

17. Isaac M, Elias B, Katz LY, Belik S-L, Deane FP, Enns MW, et al. Gatekeeper training as a preventative intervention for suicide: a systematic review. Can J Psychiatry. 2009;54(4):260-8.

18. Hvid M, Vangborg K, Sørensen HJ, Nielsen IK, Stenborg JM, Wang AG. Preventing repetition of attempted suicide-II. The Amager project, a randomized controlled trial. Nord J Psychiatry. 2011;65(5):292-8.

19. Gunnell D, Löfving S, Gustafsson JE, Allebeck P. School performance and risk of suicide in early adulthood: follow-up of two national cohorts of Swedish schoolchildren. J Affect Disord. 2011;131(1-3):104-12.

20. Milner A, Page A, LaMontagne AD. Long-term unemployment and suicide: a systematic review and meta-analysis. PLoS One. 2013;8(1):e51333.

21. Rickwood DJ, Telford NR, Parker AG, Tanti CJ, McGorry PD. headspace - Australia's innovation in youth mental health: who are the clients and why are they presenting? Med J Aust. 2014;200(2):108-11.

\section{Copyright: (C)(7)(2)}

(C) 2017 Page et al. This article is licensed under the Creative Commons Attribution-NonCommercial-ShareAlike 4.0 International Licence, which allows others to redistribute, adapt and share this work non-commercially provided they attribute the work and any adapted version of it is distributed under the same Creative Commons licence terms. See: www.creativecommons.org/licenses/by-nc-sa/4.0/ 